IZA DP No. 5387

Trade and Industrial Policies with Heterogeneous Firms: The Role of Country Asymmetries

Michael Pflüger

Stephan Russek

December 2010 


\title{
Trade and Industrial Policies with Heterogeneous Firms: The Role of Country Asymmetries
}

\author{
Michael Pflüger \\ University of Passau, \\ DIW Berlin and IZA
}

Stephan Russek

University of Passau

\section{Discussion Paper No. 5387 \\ December 2010}

\author{
IZA \\ P.O. Box 7240 \\ 53072 Bonn \\ Germany \\ Phone: +49-228-3894-0 \\ Fax: +49-228-3894-180 \\ E-mail: iza@iza.org
}

Any opinions expressed here are those of the author(s) and not those of IZA. Research published in this series may include views on policy, but the institute itself takes no institutional policy positions.

The Institute for the Study of Labor (IZA) in Bonn is a local and virtual international research center and a place of communication between science, politics and business. IZA is an independent nonprofit organization supported by Deutsche Post Foundation. The center is associated with the University of Bonn and offers a stimulating research environment through its international network, workshops and conferences, data service, project support, research visits and doctoral program. IZA engages in (i) original and internationally competitive research in all fields of labor economics, (ii) development of policy concepts, and (iii) dissemination of research results and concepts to the interested public.

IZA Discussion Papers often represent preliminary work and are circulated to encourage discussion. Citation of such a paper should account for its provisional character. A revised version may be available directly from the author. 
IZA Discussion Paper No. 5387

December 2010

\section{ABSTRACT}

\section{Trade and Industrial Policies with Heterogeneous Firms: The Role of Country Asymmetries*}

This paper explores the role of country asymmetries for trade and industrial policies with heterogeneous firms. Our analysis delivers a number of novel results. First, trade policies, infrastructure policies and industrial policies which improve the business conditions in one country have negative productivity and welfare effects on the trading partner. Second, symmetric trade liberalization is immiserizing for a trading partner whose business conditions are inferior. Third, there are gains from trade even for a country whose monopolistically competitive sector with heterogeneous firms is wiped out by the switch from autarky to trade.

JEL Classification: F12, F13, F15, L25

Keywords: firm heterogeneity, welfare, trade policies, industrial policies, business conditions

Corresponding author:

Michael Pflüger

Faculty of Economics

University of Passau

Innstrasse 27

94032 Passau

Germany

E-mail: michael.pflueger@uni-passau.de

\footnotetext{
* We thank Daniel Bernhofen, Rainald Borck, Richard Kneller, Johann Lambsdorff, Philipp Schröder, Jens Südekum, Zhihong Yu and the participants of workshops and conferences in Nottingham (GEP), Aarhus (School of Business), Glasgow (EEA) and Lausanne (ETSG) for their stimulating comments. Financial support from the Deutsche Forschungsgemeinschaft (DFG) through PF 360/5-1 is gratefully acknowledged.
} 


\section{Introduction}

Theories of heterogeneous firms and trade were developed in response to empirical challenges to old and new trade theory which emerged as micro-data sets allowed to track the production and trade at the firm level. The seminal works by Melitz (2003), Bernard, Eaton, Jensen and Kortum (2003) and Yeaple (2003) provided theoretical explanations for the findings that exporting firms are a rare species and typically larger and more productive than nonexporting firms. In an explosion of work, the scope of these theories of heterogeneous firms and trade was then considerably expanded, in particular to include endowment-driven comparative advantage (Bernard, Redding and Schott 2007), competition effects (Melitz and Ottaviano 2008) and the repercussions between trade, FDI and labor markets. ${ }^{1}$

A more recent strand of research has started to address the policy implications of the theories of heterogeneous firms and trade. This paper contributes to this nascent literature. The distinctive feature of our analysis is the focus on country asymmetries. We consider an extensive list of factors that are within the scope of trade and industrial policies and that determine the conditions of doing business: technology access, market (country) size, market entry costs, exit rate, fixed costs to serve (domestic and foreign) markets, the trade infrastructure, and also Ricardian productivity differences which imply that countries exhibit different wage levels. We use a two-sector version of the Melitz (2003) model in the spirit of the new trade theory with a competitive sector ('traditional good') in addition to the monopolistically competitive sector with heterogeneous firms ('modern/manufacturing sector'). This allows us to integrate these country asymmetries in an analytically tractable and slim way. ${ }^{2}$

Our analysis delivers a number of novel results. First, we show that trade policies, infrastructure policies and industrial policies which improve the business conditions in one country, induce a positive selection effect and bring welfare gains to that country but have a negative welfare effect on the trading partner. The possibility that a trading partner is hurt by a country's technology improvements in the modern sector was noticed by Demidova (2008). However, we show that even if technology potentials are identical in both countries, a trading partner experiences negative productivity and welfare effects due to a variety of differences in business

\footnotetext{
${ }^{1}$ Helpman (2006) and Redding (2010) survey theses developments. Davis and Harrigan (2008), Eckel and Egger (2009), Egger and Kreickemeier (2009) and Helpman and Itskhoki (2010) and Helpman, Itskhoki and Redding (2010a, 2010b) exemplify the labor market applications.

${ }^{2}$ This modelling strategy has been fruitfully be employed by Demidova (2008) and Melitz and Ottaviano (2008), among others.
} 
conditions such as entry costs, exit probabilities and/or wages. Moreover, we show that these effects get magnified as trade gets freer.

Second, we show that strong asymmetric productivity and welfare effects derive from symmetric trade liberalization. Symmetric trade liberalization exerts a positive productivity and welfare effect on the country that has superior business conditions and a negative productivity and welfare effect on the other country. Demidova (2008) has noted the possibility of immiserizing trade liberalization, but her analysis was confined to country differences in terms of their technology potential. We show that such technology differences are not necessary for such immiserization. Again, a very broad set of business conditions which are influenced by industrial policies may account for these asymmetric productivity and welfare effects.

Third, while previous analyses of heterogeneous firms and trade have been confined to settings where the countries are diversified in production, we also study the case where the switch from autarky to trade drives one country into full specialization on the traditional good. ${ }^{3}$ Our model plausibly predicts this to happen if countries are strongly asymmetric with respect to business conditions. For that case we show that there are gains from trade even for the country whose monopolistically competitive sector with heterogeneous firms is wiped out by the switch from autarky to trade. We also show that there is no immiserization trade integration in this case.

Apart from these novel conclusions, a further contribution of our analysis is to synthesize a number of previous policy findings. The tractability of our framework allows us to depict these in a very slim manner.

Previous literature. Our paper is related to an emerging literature that explores policy issues in the standard model with heterogeneous firms by Melitz (2003). As we have already noted, Demidova (2008) studies differences in the technology potential across countries. ${ }^{4}$ Her work is the one most closely related to our analysis. We shall therefore explain in detail how our results deviate from her contribution, as we go along. Baldwin (2005) and Baldwin and Forslid (2006) are also related in that they study the welfare effects of trade integration, albeit in a model which lacks the comprehensive set of business conditions that we account for. ${ }^{5}$ Demidova and Rodriguez-Clare (2009) study trade policy and welfare issues from the point of view of a small open economy. Hence, the international repercussions that emerge in a two-country setting that we highlight are absent in their paper. Chor (2009) uses a two-country model but focuses

\footnotetext{
${ }^{3}$ The full specialization case has obtained much attention in neoclassical modelling of international trade, however. See e.g. Davis and Weinstein (2001) and Schott (2003).

${ }^{4}$ See also Falvey et al. (2005).

${ }^{5}$ Feenstra and Kee (2008) address welfare as well, before turning to their empirical analysis of the Melitz model.
} 
exclusively on FDI subsidies. Jorgenson and Schröder (2008) explore the effects of exogenous tariffs and Cole and Davis (2009) analyze optimal tariffs. Pflüger and Südekum (2009) study the non-cooperative and cooperative choice of entry subsidies.

Our analysis is also related to Melitz and Ottaviano (2008) who study an alternative model which builds on the linear demand system with horizontal product differentiation developed by Ottaviano, Tabuchi and Thisse (2002). We build on the Dixit-Stiglitz (1977) framework, in contrast. This brings a benefit but also a cost. The well-known cost is that the mark-ups are constant. On the benefit side, we gain additional tractability, which is of importance since we focus on country asymmetries along many more dimensions than those envisioned by Melitz and Ottaviano (2008). ${ }^{6}$ Furthermore, neither they nor the other papers that we have referenced above consider the case where one country is completely specialized in production.

Our paper is also related to the traditional literature on trade policies, infrastructure policies and industrial policies under imperfect competition (e.g. Venables 1987, Helpman and Krugman 1987, Flam and Helpman 1987, Martin and Rogers 1995 and Baldwin et al. 2003). Of course, this literature ignores the heterogeneity of firms. Nonetheless, there are some similarities between these works and our analysis that we explain as we proceed.

The paper's structure is as follows. Our basic model is laid out in section 2. Section 3 derives the open economy equilibrium with two countries. Section 4 covers the gains from trade and our welfare and policy analyses under the usual assumption that both countries are diversified in production both before and after trade. Section 5 then turns to the case not yet addressed in the literature, where one country is forced into full specialization in the traditional industry. Section 6 offers concluding remarks.

\section{The Model}

\subsection{General set-up}

Our model is based on a version of the standard monopolistic competition model with heterogeneous firms (Melitz 2003) due to Demidova (2008). As in the new trade theory (Helpman and Krugman 1985), there are two industries. A traditional industry, $n$, produces a homogeneous numéraire good under constant returns to scale and perfect competition, and a monopolistic competitive industry, $c$, produces a continuum of differentiated manufacturing

\footnotetext{
${ }^{6}$ Melitz and Ottaviano (2008) address country differences concerning size and import barriers, only. Concerning the issue of tractability, it should be pointed out that the two-sector framework used by Melitz and Ottaviano (2008) is already much more tractable than the original Melitz (2003) model. It is not as simple to use as our framework, however.
} 
varieties under increasing returns. Each variety is produced by a single firm and firms are heterogeneous in their productivity. Labor is the only factor of production in both industries. There are $L$ workers who supply one unit of labor each. We consider an extensive list of factors which affect the conditions of doing business: we allow for country asymmetries concerning effective entry costs and exit rates, the fixed costs to serve domestic and foreign consumers, respectively, market (country) size, trade and transport infrastructure, Ricardian productivity in the competitive sector and the access to manufacturing technologies, i.e. the technology potential. We first look at a single country in autarky.

\subsection{Preferences}

Household $h$ 's preferences are defined over the homogenous good and the set of differentiated varieties, $z \in \Omega$, according to a logarithmic quasi-linear utility function with CES sub-utility ${ }^{7}$

$$
u^{h}=\beta \ln c^{h}+n^{h} \quad c^{h}=\left[\int_{z \in \Omega} q^{h}(z)^{\rho} d z\right]^{\frac{1}{\rho}}
$$

where $0<\rho<1$ and $\beta>0$ are constant parameters and where $q^{h}(z)$ expresses household $h$ 's consumption of variety $z$. The elasticity of substitution between any two varieties is given by $\sigma \equiv 1 /(1-\rho)>1$. It is well-known from Dixit and Stiglitz (1977) that $c^{h}$ can be understood as the consumption of the manufacturing aggregate with aggregate price

$$
P=\left[\int_{z \in \Omega} p(z)^{1-\sigma} d z\right]^{\frac{1}{1-\sigma}}
$$

The budget constraint of $h$ is $P c^{h}+n^{h}=y^{h}$, where $y^{h}$ denotes income. Utility maximization implies that per-capita expenditure on the manufacturing aggregate and the numéraire are given by $P c^{h}=\beta$ and $n^{h}=y^{h}-\beta$, respectively and indirect utility is $v^{h}=y^{h}-\beta \ln P+\beta(\ln \beta-1)$. Since households are identical we drop the index $h$ from now on. We assume $\beta<y$ in order to ensure that the demand for the homogeneous good is non-negative. Aggregate demand for a single variety $z$ is given by $q(z)=p(z)^{-\sigma} P^{\sigma-1} \beta L$, and total revenue for that variety is $r(z)=p(z) q(z)=[P / p(z)]^{\sigma-1} \beta L$. Overall manufacturing expenditure, $P c L$, equals $\beta L$.

\subsection{Production and pricing}

In the numéraire-sector $a$ units of labor are transformed into one unit of output. This pins down the wage, $w=1 / a$. Technologies in the modern sector are such that $l=f+q / \varphi$ units of labor

\footnotetext{
${ }^{7}$ Demidova (2008) assumes a Cobb-Douglas upper tier utility function rather than a logarithmic quasi-linear one.
} 
are needed to produce $q$ units of output. The fixed overhead labor $f$ is the same for all firms, but the variable labor requirement $(1 / \varphi)$ differs across firms. Firms have zero mass. Each firm thus faces a residual demand curve with constant price elasticity of demand $-\sigma$. Profit maximization implies that a firm with marginal cost $(w / \varphi)$ charges the price:

$$
p(\varphi)=\frac{\sigma}{\sigma-1} \frac{w}{\varphi}=\frac{w}{\rho \varphi}
$$

Revenue and profits of this firm are then given by $r(\varphi)=\beta L(\rho \varphi P / w)^{\sigma-1}$ and $\pi=r(\varphi) / \sigma-w f$, respectively. Hence, a firm with higher productivity level $\varphi$ charges a lower price, sells a larger quantity and has higher revenue and profits. Since all firm-specific variables differ only with respect to $\varphi$, the CES price index (2) can be rewritten as

$$
P=M^{1 /(1-\sigma)} p(\tilde{\varphi})=M^{1 /(1-\sigma)} \frac{w}{\rho \tilde{\varphi}} \quad \text { with } \tilde{\varphi} \equiv\left[\int_{0}^{\infty} \varphi^{\sigma-1} \cdot \mu(\varphi) d \varphi\right]^{1 /(\sigma-1)}
$$

where $M$ denotes the mass of manufacturing firms (and varieties) in the market, $\mu(\varphi)$ is the productivity distribution across these active firms with positive support over a subset of $(0, \infty)$ and $\widetilde{\varphi}$ is an average productivity level as introduced by Melitz (2003).

\subsection{Entry and exit}

There exists a mass of potential entrepreneurs who can enter the manufacturing sector subject to a sunk entry investment in terms of labor $f_{e}$. At each point in time a mass of $M^{E}$ entrepreneurs decides to enter. Upon entry these entrepreneurs learn about their productivity $\varphi$, which is drawn from a common and known density function $g(\varphi)$ with support $(1, \infty)$ and cumulative density function $G(\varphi)$. Call this the 'productivity lottery'. After the productivity is revealed, an entrant can decide to exit immediately or to remain active in the market, in which case the firm earns constant per-period profits $\pi(\varphi)$. It will exit immediately if $\pi(\varphi)<0 \leftrightarrow r(\varphi)<\sigma w f$. Only those firms remain active whose productivity draw exceeds the cutoff $\varphi^{*}>0$ at which profits are zero, $\pi\left(\varphi^{*}\right)=0$. Once in the market, every firm may be hit with constant probability $\delta$ by a lethal shock which forces it to shut down and exit. ${ }^{8}$ We focus on a stationary equilibrium without time discounting such that in each period the mass of entrants which successfully enter the market equals the mass of firms that are forced to shut down. Analytically, $\operatorname{prob}_{i} M^{E}=\delta M$, where $\operatorname{prob}_{i} \equiv 1-G\left(\varphi^{*}\right)$ is the probability to draw a productivity no smaller

\footnotetext{
${ }^{8}$ We follow Melitz (2003) and assume that once a firm is hit by a lethal shock it leaves the market instantaneously. See e.g. Hopenhayn (1992) for a dynamic analysis of firm exit.
} 
than the cutoff $\varphi^{*}$. The endogenous productivity distribution among surviving firms, $\mu(\varphi)$, is thus the conditional (left-truncated) ex-ante distribution $g\left(\varphi^{*}\right)$ on the domain $\left[\varphi^{*}, \infty\right)$.

\subsection{Equilibrium in the closed economy and parameterization}

The equilibrium within the manufacturing sector can be characterized as in Melitz (2003) by two conditions, a free entry condition (FEC) and a zero cutoff profit condition (ZCPC).

To derive the FEC note that, assuming risk neutrality, potential entrepreneurs enter the market (i.e. incur the entry cost $w f_{e}$ to participate in the productivity lottery) until the value of entry $v^{E}=E\left[\sum_{t=0}^{\infty}(1-\delta)^{t} \pi(\varphi)\right]-w f_{e}=\left[1-G\left(\varphi^{*}\right)\right] E\left[\pi(\varphi) \mid \varphi>\varphi^{*}\right] / \delta-w f_{e}$ is driven to zero. Using $\pi(\varphi)=r(\varphi) / \sigma-w f$ and $r(\varphi)=(\varphi / \tilde{\varphi})^{\sigma-1} r(\tilde{\varphi})$ where $\tilde{\varphi} \equiv E\left[\varphi^{\sigma-1} \mid \varphi>\varphi^{*}\right]^{1 /(\sigma-1)}$ is a measure of average productivity, and imposing $v^{E}=0$, the FEC can be derived as $\pi(\tilde{\varphi})=\delta w f_{e} /\left[1-G\left(\varphi^{*}\right)\right]$. The ZCPC states that the cutoff firm makes zero profits, $\pi\left(\varphi^{*}\right)=0 \leftrightarrow r\left(\varphi^{*}\right)=\sigma w f$. Using $\pi(\tilde{\varphi})=[r(\tilde{\varphi}) / \sigma]-w f \quad$ and $r\left(\varphi^{*}\right)=\left(\varphi^{*} / \tilde{\varphi}\right)^{\sigma-1} r(\tilde{\varphi})$, this condition can also be expressed as a function of the average productivity level $\tilde{\varphi}$ : $\pi(\tilde{\varphi})=\left\lfloor\left(\tilde{\varphi} / \varphi^{*}\right)^{\sigma-1}-1\right\rfloor w f$. The equilibrium is determined by the cutoff productivity $\varphi^{*}$ which simultaneously satisfies the FEC and the ZCPC. In order to conform to the empirical evidence and to obtain closed-form solutions we assume Pareto-distributed productivities, $G(\varphi)=1-\left(\varphi_{\min } / \varphi\right)^{k}$ and $g(\varphi)=G^{\prime}(\varphi)=k \varphi_{\min }^{k} \varphi^{-k-1}$ where $\varphi_{\min }>0$ is the lower bound for productivity draws and $k>1$ is the shape parameter. ${ }^{9}$ The ex post probability of productivities is then conditional on successful market entry, $\mu(\varphi)=g(\varphi) /\left[1-G\left(\varphi^{*}\right)\right]=k \varphi^{* k} \varphi^{-(k+1)}$ if $\varphi>\varphi^{*}$ and $\mu(\varphi)=0$ otherwise. Moreover, $\tilde{\varphi}=[k /(k-(\sigma-1))]^{1 /(\sigma-1)} \varphi^{*}$, where we assume $k>\sigma-1$. Using these expressions in FEC and ZCPC yields the autarky equilibrium cutoff:

$$
\varphi_{\text {aut }}^{*}=\left[\frac{(\sigma-1)}{(k-\sigma+1)} \frac{f}{f_{e}} \frac{\varphi_{\min }^{k}}{\delta}\right]^{\frac{1}{k}}
$$

The equilibrium cutoff is independent of the number of workers $L$, positively related to the elasticity of substitution $\sigma$, the fixed labor $f$ to serve the market and the lower bound $\varphi_{\min }$ and

\footnotetext{
${ }^{9}$ For empirical support see e.g. Del Gatto et al. (2006) and Ikeda and Suoma (2009). The Melitz-model with the Pareto-parameterization has been popularized by Bernard et al. (2003), Helpman et al. (2004), Baldwin (2005), Helpman et al. (2008) and Melitz and Ottaviano (2008).
} 
negatively related to the fixed investment of labor at the entry stage $f_{e}$, the death rate $\delta$, as well as the Pareto-shape parameter $k$, as in Melitz (2003) and Demidova (2008). ${ }^{10}$ Moreover, $\varphi_{\text {aut }}^{*}$ is unaffected by the labor coefficient in the competitive sector $a$ since this coefficient affects the wage and hence the fixed costs both to enter and serve the market equiproportionately. We show below that countries' labor coefficients affect the cutoffs in the open economy equilibrium, however.

Once the equilibrium cutoff is determined, all other endogenous variables are easily derived (see appendix A). The autarky price level which we need for future reference is given by $P_{\text {aut }}=(\beta L / \sigma f)^{1 /(1-\sigma)} w^{\sigma /(\sigma-1)}\left(1 / \rho \varphi_{\text {aut }}^{*}\right)$ and the indirect utility of a household is then:

$$
v_{\text {aut }}=w-\beta \ln \left[\left(\frac{\beta L}{\sigma f}\right)^{\frac{1}{1-\sigma}} w^{\frac{\sigma}{\sigma-1}}\left(\frac{1}{\rho \varphi_{\text {aut }}^{*}}\right)\right]+\beta(\ln \beta-1)
$$

Countries with a greater endowment of labor $L$ and a higher cutoff are better off. Moreover, it is readily derived that wage increases resulting from productivity increases in the numéraire sector raise (lower) the indirect utility iff $(1 / a)>(<) \beta \sigma /(\sigma-1)$.

\section{The Open Economy}

\subsection{Assumptions}

We now turn to an open economy setting with two countries $i, j \in[H, F]$, say home $H$ and foreign $F$. These two countries potentially differ in a number of characteristics which determine the conditions to do business. There may be differences in country size $L_{i}$ and in the labor coefficient in the competitive sector $a_{i}$. Technologies in the manufacturing sector may be different: we assume that entrants in country $i$ draw their productivity from a country-specific Pareto-distribution with common shape parameter $k$ but with potentially different lower bounds, $\varphi_{\min i} \cdot{ }^{11}$ Exit rates $\delta_{i}$ may also be asymmetric. We also allow the fixed labor input for entry in the manufacturing sector $f_{e, i}$ and the fixed labor input $f_{i}$ to serve domestic markets to differ

\footnotetext{
${ }^{10}$ The statements concerning $\varphi_{\min }$ and $k$ refer to versions of the Melitz-model with Pareto-distributed productivities (cf. the references in footnote 4 ).

${ }^{11}$ Demidova's (2008) treatment of productivity differences in the manufacturing sector is more general than ours. She allows for general country-specific productivity distributions $G_{i}(\varphi)$ which may dominate the productivity distribution $G_{j}(\varphi)$ of the other country in terms of the hazard rate order. Since we consider further asymmetries and since we want to keep the model tractable, we have chosen to sacrifice some generality here.
} 
across countries. If (after learning its productivity $\varphi_{i}$ ) a firm from country $i$ decides to export to region $j$ it faces an additional country-specific fixed cost $f_{x i}$, on top of the domestic perperiod fixed costs $f_{i}$ that accrue irrespectively of export status. Moreover, firms have to incur variable iceberg costs to serve foreign consumers: for one unit to arrive in $j$, a firm from country $i$ has to ship $\tau_{i j}>1$ units. We shall allow for the possibility that $\tau_{i j} \neq \tau_{j i}$, e.g. due to different trade policies or trade infrastructures. Trade in the competitive sector is costless. As long as both countries produce this good, an assumption that we shall maintain throughout the paper, the law of one price dictates that the foreign wage is tied to the domestic wage, $W \equiv w_{F} / w_{H}=a_{H} / a_{F}$ where $W$ denotes the relative foreign wage. Note that $w_{i}=1 / a_{i}$ by our choice of the numéraire. Hence, we do not impose factor prize equalization.

\subsection{Domestic cutoffs and export cutoffs}

Following the approach pioneered in Demidova (2008) we now derive the domestic cutoff productivities $\varphi_{H}^{*}$ and $\varphi_{F}^{*}$ drawing on the conditions of free entry and zero cutoff profits which become interdependent across countries in the open economy. If a manufacturing firm from country $i$ exports to country $j$, its profits from exporting are given by $\pi_{x i}(\varphi)=r_{x i}(\varphi) / \sigma-w_{i} \cdot f_{x i}$ where $r_{x i}(\varphi)=\left(\tau_{i j} w_{i} / \rho \varphi\right)^{1-\sigma} P_{j}^{\sigma-1} \beta L_{j}$ is the export revenue. There is a critical productivity threshold $\varphi_{x i}^{*}$ where such a firm just breaks even on the export market, i.e. $\pi_{x i}\left(\varphi_{x i}^{*}\right)=0 \Leftrightarrow r_{x i}\left(\varphi_{x i}^{*}\right)=\sigma w_{i} f_{x i}$. We call this the export ZCPC. Furthermore, a manufacturing firm from country $i$ that serves her home market $i$ derives profits $\pi_{i}(\varphi)=r_{i}(\varphi) / \sigma-w_{i} f_{i}$ where $r_{i}(\varphi)=\left(w_{i} / \rho \varphi\right)^{1-\sigma} P_{i}^{\sigma-1} \beta L_{i}$ is the associated revenue. The cutoff $\varphi_{i}^{*}$ where this firm breaks even is defined by $\pi_{i}\left(\varphi_{i}^{*}\right)=0 \Leftrightarrow r_{i}\left(\varphi_{i}^{*}\right)=\sigma w_{i} f_{i}$. We call this the domestic ZCPC. The revenue equations imply a link between export cutoffs and domestic cutoffs, $\varphi_{x H}^{*}=W^{-\sigma /(\sigma-1)} t_{H} \varphi_{F}^{*}$ and $\varphi_{x F}^{*}=W^{\sigma /(\sigma-1)} t_{F} \varphi_{H}^{*}$ where $t_{i} \equiv \tau_{i j}\left(f_{x i} / f_{j}\right)^{1 /(\sigma-1)}$ (see appendix B).

Throughout the paper we impose the assumption $f_{x i} / f_{j}>\tau_{i j}^{1-\sigma}\left(w_{j} / w_{i}\right)^{\sigma}\left(\varphi_{i}^{*} / \varphi_{j}^{*}\right)^{\sigma-1}$ to ensure that only firms that produce in the domestic market can export (i.e. $\varphi_{x i}^{*}>\varphi_{i}$ ).

The free entry condition (FEC) for country $i$ commands that firms enter the market until the value of entry is zero, $\operatorname{prob}_{i} E\left[\pi_{i}(\varphi) / \delta_{i} \mid \varphi>\varphi_{i}^{*}\right]+\operatorname{prob}_{x i} E\left[\pi_{x i}(\varphi) / \delta_{i} \mid \varphi>\varphi_{x i}^{*}\right]=w_{i} f_{e i}$. The first term on the LHS formalizes the expected profits on the domestic market and the second term 
expresses expected profits on the export market where $\operatorname{prob}_{x i} \equiv 1-G_{i}\left(\varphi_{x i}^{*}\right)$ denotes the probability for a productivity draw high enough to enter the export market. The RHS expresses the entry costs. Using the FECs and the domestic and export ZCPC for each of the two countries, employing the links between export cutoffs and domestic cutoffs, and imposing the Pareto parameterization the equilibrium cutoff productivities are derived as (see appendix C):

$$
\begin{gathered}
\varphi_{H}^{*}=\left[\frac{(\sigma-1)}{(k-\sigma+1)} \frac{f_{H}}{f_{e H}} \frac{\varphi_{\min H}^{k}}{\delta_{H}} \cdot\left[\frac{1-\Phi_{F} \Phi_{H}}{1-\Delta^{\delta, f_{e}, \varphi_{\min }, w} \cdot \Phi_{H}}\right]\right]^{\frac{1}{k}}=\varphi_{H, \text { aut }}^{*} \cdot\left[\frac{1-\Phi_{F} \Phi_{H}}{1-\Delta^{\delta, f_{e}, \varphi_{\min }, w} \cdot \Phi_{H}}\right]^{\frac{1}{k}} \\
\varphi_{F}^{*}=\left[\frac{(\sigma-1)}{(k-\sigma+1)} \frac{f_{F}}{f_{e F}} \frac{\varphi_{\min F}^{k}}{\delta_{F}} \cdot\left[\frac{1-\Phi_{F} \Phi_{H}}{1-\Phi_{F} / \Delta^{\delta, f_{e}, \varphi_{\min }, w}}\right]\right]^{\frac{1}{k}}=\varphi_{F, a u t}^{*} \cdot\left[\frac{1-\Phi_{F} \Phi_{H}}{1-\Phi_{F} / \Delta^{\delta, f_{e}, \varphi_{\min }, w}}\right]^{\frac{1}{k}}
\end{gathered}
$$

where the $\Phi_{i} \equiv \tau_{i j}^{-k}\left(f_{j} / f_{x i}\right)^{(k-\sigma+1) /(\sigma-1)}$ are measures of trade openness which rise as variable trade costs $\tau_{i j}$ and the fixed cost ratio $f_{x i} / f_{j}$ (i.e. the fixed cost that a firm from $i$ faces to serve the foreign market in relation to the fixed costs of a foreign competitor) fall. We shall assume that $f_{x i} / f_{j}>1$ which implies that $0 \leq \Phi_{i}<1$. The parameter $\Delta^{\delta, f_{e}, \varphi_{\min }, w} \equiv D F_{e} T^{k} W^{\frac{\sigma k}{\sigma-1}}$ captures international differences (ratios) concerning exit rates $D \equiv \delta_{F} / \delta_{H}$, entry investments $F_{e} \equiv f_{e F} / f_{e H}$, technologies in the manufacturing sector as proxied by the respective lower productivity bounds of the Pareto-distribution $T \equiv \varphi_{\min H} / \varphi_{\min F}$ and wage differentials $W \equiv w_{F} / w_{H}=a_{H} / a_{F}$ caused by productivity differences in the competitive sector. $\Delta^{\delta, f_{e}, \varphi_{\min }, w}$ rises when home business conditions turn in favor of domestic firms (i.e. when market entry becomes less expensive in home or market exit is less probable, when technological conditions are such that the domestic productivity lottery 'dominates' the foreign one, or when domestic wages fall relative to foreign wages).

Absent international differences in business conditions (with $\Delta^{\delta, f_{e}, \varphi_{\min }, w}=1$ and $\Phi_{H}=\Phi_{F}=\Phi$ ) the cutoffs are given by $\varphi_{i}^{*}=\varphi_{i, \text { aut }}^{*}(1+\Phi)^{1 / k}$ both for $H$ and for $F$ as in Melitz (2003). When we allow for country asymmetries, we have to impose the condition $1 / \Phi_{H}>\Delta^{\delta, f_{e}, \varphi_{\min }, w}>\Phi_{F}$ to ensure meaningful solutions ( $\operatorname{such}$ that $\varphi_{i}^{*}>0$ for $i=H, F$ ). Intuitively, the overall business conditions for the manufacturing sectors in the two countries must not be too different. Notice that it clearly is conceivable that business conditions are so disparate that a country, call it the 'laggard', is driven into full specialization in the traditional industry and that all manufactures are produced in the 'leading' country. We take this case up in section 5. 
Once the domestic equilibrium cutoffs are determined, the export cutoffs are immediately implied by the links $\varphi_{x H}^{*}=W^{-\sigma /(\sigma-1)} t_{H} \varphi_{F}^{*}$ and $\varphi_{x F}^{*}=W^{\sigma /(\sigma-1)} t_{F} \varphi_{H}^{*}$. The conditional probability to become an exporter in country $i$ can then be derived from $\operatorname{cprob}_{x i} \equiv \operatorname{prob}_{x i} / \operatorname{prob}_{i}=\left(\varphi_{i}^{*} / \varphi_{x i}^{*}\right)^{k}$. The average productivity of domestic firms $\tilde{\varphi}_{i}$ and the average productivity of exporting firms $\tilde{\varphi}_{x i}$ follow from $\tilde{\varphi}_{i}=[k /(k-(\sigma-1))]^{1 /(\sigma-1)} \varphi_{i}^{*}$ and $\tilde{\varphi}_{x i}=[k /(k-(\sigma-1))]^{1 /(\sigma-1)} \varphi_{x i}^{*}$. Finally, the average profits can be calculated as $\pi\left(\widetilde{\varphi}_{i}\right) \equiv \pi\left(\widetilde{\varphi}_{i}\right)+\operatorname{cprob}_{x i} \pi_{x i}\left(\widetilde{\varphi}_{x i}\right)=\frac{(\sigma-1) w_{i}}{k-(\sigma-1)}\left(f_{i}+\operatorname{cprob}_{x i} f_{x i}\right)$.

\subsection{Trade balance and open economy equilibrium}

To complete the characterization of the open economy equilibrium we have to impose balanced trade. From the perspective of the domestic economy, this is given by:

$$
\operatorname{cprob}_{x H} M_{H} r_{x H}\left(\tilde{\varphi}_{x H}\right)=\operatorname{cprob}_{x F} M_{F} r_{x F}\left(\tilde{\varphi}_{x F}\right)+\left(w_{H}-\beta\right) L_{H}-\left(1-\gamma_{H}\right) L_{H} / a_{H}
$$

The LHS of eq. (8) gives the value of country $H$ 's manufacturing exports and the first term on the RHS gives the value of manufacturing imports. The second and third term on the RHS are the values of domestic consumption and production of the traditional good, respectively. Any imbalance in trade in manufacturing must be matched by a trade surplus or deficit in this numéraire. The resulting firm masses are derived and reported in appendix C. Country $i$ 's CES price index is given by $P_{i}=\left[\int_{0}^{\infty} p_{i}^{1-\sigma} M_{i} \mu_{i}(\varphi) d \varphi+\int_{0}^{\infty}\left(\tau_{j i} p_{j}\right)^{1-\sigma} M_{x j} \mu_{x j}(\varphi) d \varphi\right]^{1 /(1-\sigma)} \quad$ which can be rewritten as $P_{i}=\left(\beta L_{i} / \sigma f_{i}\right)^{1 /(1-\sigma)} w_{i}^{\sigma /(\sigma-1)}\left(\rho \varphi_{i}^{*}\right)^{-1}$ (see appendix D). The indirect utility follows as:

$$
v_{i}=w_{i}-\beta \ln \left[\left(\frac{\beta L_{i}}{\sigma f_{i}}\right)^{\frac{1}{1-\sigma}} w_{i}^{\frac{\sigma}{\sigma-1}}\left(\frac{1}{\rho \varphi_{i}^{*}}\right)\right]+\beta(\ln \beta-1)
$$

\section{$4 \quad$ Welfare and Policy Analysis}

This section assumes that the two countries are diversified in production before and after trade. Section 5 covers the case where one country becomes fully specialized on the traditional good. Section 4.1 begins with the gains from trade. The policy analyses that we perform in sections 4.2. to 4.5 start from an international equilibrium as characterized in section 3. First we take up trade and infrastructure policies that are unilaterally performed by one country (section 4.2.) and 
then address symmetric trade liberalization (section 4.3). Section 4.4 addresses the effects of industrial policies and section 4.5. highlights the trade cost sensitivity of such policies.

\subsection{The gains from trade}

The welfare effect of opening up an economy from the state of autarky to trade is unambiguously positive as stated in

PROPOSITION 1. (Gains from trade). Both countries have higher welfare under free trade than under autarky.

Proof. Proposition 1 is immediately implied by eqs. (7) and (9). By (7) the equilibrium cutoffs are higher in the two countries under trade than under autarky. The price level is then lower in both countries under trade than under autarky. This entails by eq. (9) that welfare (indirect utility) is higher under trade than under autarky, $v_{i}-v_{\text {aut }}>0$.

Proposition 1 generalizes previous findings. Melitz (2003) has proved the gains from trade for the case of identical countries and Demidova (2008) has extended this proof to the case of countries which are asymmetric with respect to technologies in the modern sector. We generalize this result to economies which are asymmetric with respect to a comprehensive set of factors that determine the conditions to do business. In our generalized model, the welfare gain associated with the move from autarky to trade derives fully from the selection effect which drives up the productivity cutoffs as described in Melitz (2003).

\subsection{Unilateral trade integration and infrastructure policies}

We now turn to analyze the effects associated with a reduction of trade costs between the two countries. We start with the case of unilateral trade integration where one country (say $j$ ) allows firms located in $i$ better access to its consumers. This is captured by an increase in $\Phi_{i}$ which may stem either from reductions in variable trade costs $\tau_{i j}$ and/or from reductions in the fixed export costs $f_{x i}$. Our results are summarized in:

PROPOSITION 2. (Welfare gains and losses from unilateral trade integration). (i) $A$ unilateral reduction in trade costs to serve market $j$ (captured by $d \Phi_{i}>0$ ) leads to welfare gains in country $i$ and welfare losses in country $j$. (ii) The effect of unilateral trade integration on country $i$ 's productivity is the stronger, the more favorable are the business conditions in $i$ relative to $j$. 
Proof. To prove the first part of proposition 2 first note that, by eq. (7), $\partial \varphi_{i}^{*} / \partial \Phi_{i}>0$ and $\partial \varphi_{j}^{*} / \partial \Phi_{i}<0$. Taking this into account in the indirect utility, eq. (9), immediately implies our claim. The second part follows from noting that $d\left(\frac{\partial \varphi_{H}^{*}}{\partial \Phi_{H}} \frac{\Phi_{H}}{\varphi_{H}^{*}}\right) / d \Delta^{\delta, f_{e}, \varphi_{\min }, w}>0$.

The intuition behind proposition 2(i) is the following. Granting firms located in country $i$ better access to consumers located in country $j$ raises the profitability to produce manufacturing varieties in country $i$. This stimulates entry and tightens competition in $i$. The least productive firms are driven out of the market in $i$ and the cutoff is raised. This benefits domestic consumers. Firms in $i$ also gain a competitive advantage over firms located in $j$. The foreign market becomes less profitable for local (foreign) firms. This reduces the incentive for foreign firms to enter the market. Competition is thus weakened resulting in a reduction in the foreign productivity cutoff which negatively affects the welfare of foreign consumers.

The results comprehended by proposition 2(i) involve trade and infrastructure policies. Reductions in variable trade costs $\left(d \tau_{i j}<0\right)$ can both be thought of as being due to lower import tariffs or similar trade costs or due to infrastructure policies (such as greater and more efficient harbors or airports) in country $j$.

Proposition 2(ii) carries an important message for trade negotiations: it reveals that the incentive to request better market access to a foreign country rises the more favorable is one's own business environment.

\subsection{Symmetric trade integration}

We now turn to the case of a symmetric reduction in trade costs $d \Phi_{H}=d \Phi_{F}>0$. Note that this comprehends a reduction in variable (iceberg) trade costs and/or a reduction in fixed costs to serve the foreign market (since $\partial \Phi_{i} / \partial \tau_{i j}<0$ and $\partial \Phi_{i} / \partial f_{x i}<0$, respectively). We obtain:

PROPOSITION 3. (Welfare gains and losses from symmetric trade integration). $A$ symmetric reduction in trade costs $\left(d \Phi_{H}=d \Phi_{F}>0\right)$ leads to an immiserization of one country and welfare gains in the other country if $\Delta^{\delta, f_{e}, \varphi_{\min }, w}<\left(\Phi_{H}+\Phi_{F}\right) /\left(1+\Phi_{H}^{2}\right)$ (then $H$ loses) or if $\Delta^{\delta, f_{e}, \varphi_{\min }, w}>\left(1+\Phi_{F}^{2}\right) /\left(\Phi_{H}+\Phi_{F}\right)$ (then $F$ loses). Otherwise both countries reap welfare gains. 
Proof. A country' welfare rises (falls) when the productivity cutoff rises (falls). Totally differentiate $\varphi_{i}^{*}=\varphi_{i}^{*}\left(\Phi_{i}, \Phi_{j}\right)$, take the derivatives of the equilibrium cutoffs $\partial \varphi_{i}^{*} / \partial \Phi_{i}$ and $\partial \varphi_{i}^{*} / \partial \Phi_{j}$ for $i, j$, impose $d \Phi_{H}=d \Phi_{F}>0$, and then explore the sign of the derivatives.

This proposition delivers the important result that the possibility of immiserization through trade integration that was first noted by Demidova (2008, proposition 1) is far more general than conceived by her. Demidova allows technology potentials in the manufacturing sector to differ across countries and she shows that it is possible that the 'laggard' (the country with the inferior technology potential) may lose from falling trade costs. We generalize this result in two important dimensions.

First, we show that asymmetric business conditions in a much more comprehensive sense are accountable for the possibility of immiserization. In fact, there is the possibility of immiserization even without differences in technology potentials in the modern sector. To see this consider the case where country $F$ is the laggard and $H$ is the leading country and remember that $\Delta^{\delta, f_{e}, \varphi_{\min }, w} \equiv D F_{e} T^{k} W^{\frac{\sigma k}{\sigma-1}}$. Then note that the condition $\Delta^{\delta, f_{e}, \varphi_{\min }, w}>\left(1+\Phi_{F}^{2}\right) /\left(\Phi_{H}+\Phi_{F}\right)$ can be fulfilled even if $T \equiv \varphi_{\min H} / \varphi_{\min F}=1$, indicating identical technology potentials ${ }^{12}$, if entry investments are relatively more favorable in country $H$ (i.e. if $F_{e} \equiv f_{e F} / f_{e H}$ exceeds unity strongly enough), the default risk in $H$ is relatively low (i.e. if $D \equiv \delta_{F} / \delta_{H}$ exceeds unity strongly enough) and/or wages are relatively low in country $H$ (i.e. $W \equiv w_{F} / w_{H}=a_{H} / a_{F}$ exceeds unity strongly enough) such that the left-hand side (LHS) is large. Moreover note that this condition is more easily fulfilled if the right-hand side (RHS) is small, which is the case if firms from $H$ have easy access to consumers in $F$ (i.e. $\Phi_{H}$ is large) or, when trade costs are identical and low (i.e. high $\Phi_{F}=\Phi_{H}$ ). Moreover, the RHS is low, if it is difficult for firms from $F$ to accede consumers in $H .{ }^{13}$ Also note that size differences as proxied by the number of workers, $L_{H}$ and $L_{F}$, are inconsequential. ${ }^{14}$

\footnotetext{
${ }^{12}$ Remember that Demidova (2008) allows technology potentials to differ in a general sense. Our specification which only involves the support of the technology distribution suffices to make the point, however.

${ }^{13}$ Caveat: this holds when $2 \Phi_{H} \Phi_{F}-\left(1-\Phi_{F}^{2}\right)<0$.

${ }^{14}$ The inconsequentiality of country size was already found in Baldwin and Forslid (2006), see also Baldwin (2005). However, these authors concluded that symmetric trade integration must raise welfare in both countries. This difference to our findings can be explained by noting that these authors did neither account for differences in technology potentials nor the comprehensive set of business conditions that we highlight.
} 
Second, our analysis is general in the sense that we allow the symmetric trade integration to proceed from an initial situation where firms face different conditions to accede consumers in the other country, i.e. $\Phi_{H}$ and $\Phi_{F}$ may differ in the initial equilibrium.

\subsection{Industrial policies and business conditions in the open economy}

Industrial policies have a direct effect on business conditions. Business conditions, in turn, impact on the productivity of firms and on country welfare under international trade. We have:

\section{PROPOSITION 4. (The effect of industrial policies and business conditions under trade).}

Lower domestic entry investments $f_{e i}$, lower labor productivity in the traditional sector $1 / a_{i}, a$ lower default risk $\delta_{i}$ and/or greater technological potential $\varphi_{\min i}$ in country $i$ raises the cutoff productivity and welfare in this country and decreases productivity and welfare in country $j$.

Proof. This proposition follows immediately by considering the effects of changes in $f_{e i}$, $1 / a_{i}, \delta_{i}$ and $\varphi_{\min i}$ on eq. (7) and (9).

Intuitively, any improvement in business conditions in country $i$, such as a better technology potential, lower entry investments, a lower exit probability and/or lower wages, raises the profitability of the domestic market and gives local firms a competitive edge over their foreign competitors. This stimulates entry in country $i$ and reduces the incentive to enter the manufacturing industry in country $j$, which sets in a selection effect that leads to higher cutoffs and welfare in $i$ and lower cutoffs and welfare in $j$ (similarly to the case of unilateral improvements in market access that we discussed before).

Proposition 4 provides a considerable generalization of the finding that productivity improvements in one country hurt the other country (Demidova 2008, proposition 2). In fact our proposition shows that the very same result holds with respect to competitive advantages due to lower wages, a lower exit risk and easier market entry. Importantly, we show that asymmetric effects on productivities and on welfare obtain in the two countries even without differences in technology potentials that were envisioned by Demidova (2008).

In contrast to the factors considered in proposition 4 the effect of changes in the domestic fixed labor input necessary to serve the domestic market has an ambiguous effect on the domestic productivity cutoff, but an unambiguous effect on welfare as stated in: 
PROPOSITION 5. (The effect of domestic fixed labor input under trade). An increase in domestic fixed labor inputs $\left(f_{i}\right)$ leads to $(i)$ an increase in the domestic productivity cutoff iff the domestic market is sufficiently protected from foreign competition, i.e. iff $\Phi_{H} \Phi_{F}<(\sigma-1) /(k-\sigma)$, (ii) unambiguous welfare losses in country $i$, and (iii) an unambiguous increase in the cutoff productivity and welfare in country $j$.

Proof. The method of proof follows the one employed to prove the previous proposition.

Proposition 5 shows a remarkable difference to our finding for the closed economy. In the closed economy, an increase in $f$ necessarily drives up the productivity cutoff (see eq. (5)) due to a stronger selection effect which drives the least efficient firm out of the market. In the open economy, an increase in $f_{i}$ has a further effect, it facilitates the access of foreign firms to the domestic market, as $d \Phi_{j} / d f_{i}>0$. This implies a competitive disadvantage for domestic firms vis-à-vis their foreign competitors whose effect it is to reduce the productivity cutoff. This leads to the ambiguity. However, the effect on domestic welfare is unambiguously negative, as the increase in the fixed labor input reduces the domestic number of firms $M_{t i}$ and hence the product variety available. Furthermore, the impact on foreign productivity and welfare is positive, as firms from $j$ now enjoy a comparative advantage.

Propositions 4 and 5 are of crucial importance from a policy perspective. Fixed investments that are needed to enter and serve the domestic market and the technology potential can be influenced by industrial policy. For example the necessary fixed investments to start and do business are associated with a country's level of corruption, the costs to enforce contracts, the costs to provide protection against crime, product piracy and product imitation. Technology policies have an influence on a country's technological potential. Crucially, any improvement from the point of view of one economy has a negative welfare effect on the other economy.

\subsection{Trade cost sensitivity of industrial policies}

Policymakers should be aware of how sensitive the effects of industrial policies (noted in propositions 4 and 5) are with respect to the level of trade integration. We can show:

PROPOSITION 6. (Trade cost sensitivity of policies). (i) Consider the effect of changes in country $i$ 's technology potential, fixed market entry investment, exit rate or wage rate on the domestic productivity cutoff (as captured by $d \varphi_{i}^{*} / \varphi_{i}^{*}$ ). (i-a) Suppose $\Phi_{F}=\Phi_{H}=\Phi$. The effect of any such change is the greater, the greater is the level of trade freeness ( $\Phi)$. (i-b) Suppose 
$\Phi_{F} \neq \Phi_{H}$. The effect of any such change is the greater, the higher is $\Phi_{i}$, i.e. the better is the market access of firms from country $i$ to market $j$. The effect of any such change is insensitive to $\Phi_{j}$. (ii) Consider the effect of changes in country $i$ 's fixed labor input on the domestic productivity cutoff. (ii-a) If $\Phi_{H} \Phi_{F}<(\sigma-1) /(k-\sigma)$, changes in the domestic productivity get smaller by trade integration. (ii-b) Otherwise, the effect on the domestic productivity cutoff is the greater, the higher is $\Phi_{i}$.

Proof. The proposition follows from differentiation of eq. (7).

Part (i-a) of proposition 6 carries the important message that the impact of policies that affect the conditions to do business is magnified when the general level of trade freeness is higher. This finding has previously been obtained in models of the new trade theory and the new economic geography with homogeneous firms (cf. Helpman and Krugman 1985; Baldwin et al. 2003), the underlying mechanism being the same one as here. Our analysis extends this result to a comprehensive set of factors affecting business conditions. Part (i-b) of proposition 6 is entirely novel. It reveals that domestic policies are more powerful when domestic firms have easy access to foreign markets. Part (ii-a) reveals that if a country is sufficiently protected from international trade (i.e., if $\Phi_{H} \Phi_{F}<(\sigma-1) /(k-\sigma)$ holds true), the (positive) impact of higher fixed labor inputs on the domestic productivity is smaller at higher levels of trade freeness. In case (ii-b), where the country is sufficiently exposed to international trade (i.e., if $\left.\Phi_{H} \Phi_{F}>(\sigma-1) /(k-\sigma)\right)$, it becomes evident that trade integration even magnifies the (negative) impact of higher domestic fixed labor inputs.

\section{$5 \quad$ Full specialization in the traditional industry}

Our analysis has so far rested on the assumption that the two countries are diversified in production both under autarky and under trade, each country is assumed to have an active manufacturing sector in addition to a traditional industry. However, we have already noted that it is conceivable that one country (the 'laggard') may be forced into specialization in the traditional industry if asymmetries are very strongly in favor of doing business in the other country (the 'leading economy'). This section considers this possibility. We shall assume that the 'leading country' is still diversified in production. We highlight the key results here and refer the reader to appendix $\mathrm{E}$ for an extended technical exposition of this case. 
Condition for specialization. We start out with an exploration of the condition under which one country is driven into full specialization in the traditional industry. Using eq. (D1) and imposing $M_{i} \geq 0$, both countries have manufacturing producers if $\Phi_{F}<\Delta^{L, \varphi^{*}}<1 / \Phi_{H}$. By substituting $\Delta^{L, \varphi^{*}} \equiv \lambda \cdot\left(\Delta^{\delta, f_{e}, \varphi_{\min }, w}-\Phi_{F}\right) /\left(1-\Delta^{\delta, f_{e}, \varphi_{\min }, w} \cdot \Phi_{H}\right)$, where $\lambda \equiv L_{H} / L_{F}$ is the ratio of labor endowment in $H$ relative to $F$, and solving for $\Delta^{\delta, f_{e}, \varphi_{\min }, w}$, this condition for nonspecialization in both countries can be rewritten as ${ }^{15}$

$$
\Phi_{F} \frac{\lambda+1}{\lambda+\Phi_{H} \Phi_{F}}<\Delta^{\delta, f_{e}, \varphi_{\min }, w}<\frac{1}{\Phi_{H}} \frac{1+\lambda \Phi_{H} \Phi_{F}}{1+\lambda}
$$

Outside this range, one country will be fully specialized in the production of the traditional good: country $H$ is fully specialized if $\Delta^{\delta, f_{e}, \varphi_{\min }, w}<\Phi_{F}(\lambda+1) /\left(\lambda+\Phi_{H} \Phi_{F}\right)$ and country $F$ is fully specialized if $\Delta^{\delta, f_{e}, \varphi_{\min }, w}>\left(1+\lambda \Phi_{H} \Phi_{F}\right) /\left[(1+\lambda) \cdot \Phi_{H}\right]$. On inspection of these conditions we see that countries are fully specialized on the homogeneous good if business conditions are strongly against doing business in that economy (i.e. if wages are high, the economy is small, fixed investments needed for domestic and foreign market supply are high, entry investment is high, the exit rate is high, the technology potential is weak and trade access is difficult).

Gains from trade. The switch from autarky to trade may force one country into full specialization in the traditional industry. Even in this case there are gains from trade to both countries, however. We can state:

PROPOSITION 7. (Gains from trade under specialization). Both countries have higher welfare under international trade than under autarky even if trade opening forces one country into full specialization in the traditional industry whereas the other country is diversified in production.

Proof. Since we assume that both countries produce the traditional good both under autarky and under trade (such that a consumer has the same wage under autarky and trade), the welfare comparison boils down to a comparison of the price levels. We show in appendix E that even if a country is forced into full specialization by opening up to trade, its price level is lower than under autarky (where it produces both types of goods). The country which produces both types of goods has a lower price level for the same reason as in proposition 1. Hence, it holds true for that $v_{s, i}-v_{\text {aut }, i}>0$ for both countries.

\footnotetext{
${ }^{15}$ This restriction binds more strongly than the restriction for meaningful cutoff productivities (see section 3.2.).
} 
To the best of our knowledge, proposition 7 is entirely novel. The country which is driven into full specialization in the traditional industry benefits from the productivity increase of the trading partner. Our proposition shows that this beneficial effect is so strong that it compensates for the fact that the 'laggard' country has to incur trade costs for all manufacturing goods.

No immiserizing trade integration with full specialization. Proposition 3 which was derived under the assumption that both countries are diversified in production showed that one country may experience immiserization under trade integration. This result no longer holds true under specialization. In fact, it is immediate to see that a country that is and remains specialized during trade integration always experiences welfare gains through trade cost savings. We thus have:

PROPOSITION 8. (No immiserization under trade integration). If trade opening forces one country into full specialization in the traditional industry whereas the other country is diversified in production, no country is worse off by trade integration.

Proof: The welfare of a country increases when the price level falls. Use the price indices under specialization (as stated in appendix E) to see that they do not rise by trade integration.

The intuition of this result is straightforward. The country that is fully specialized on the production of the homogeneous good unambiguously gains from trade integration because the access to the manufacturing goods that are produced by the other country becomes cheaper. The country that hosts both industries will not be worse off under trade integration.

\section{Conclusion}

This paper explores the role of country asymmetries for trade and industrial policies in a twosector general equilibrium model with heterogeneous firms. We consider an extensive list of factors that determine the conditions of doing business: technology access, market (country) size, market entry costs, exit rates, fixed costs to serve markets, the trade infrastructure, and Ricardian productivity differences. Our analysis delivers a number of novel results. First, trade policies, infrastructure policies and industrial policies which improve the business conditions in one country have negative productivity and welfare effects on the trading partner. Second, symmetric trade liberalization is immiserizing for a trading partner whose business conditions are inferior. Third, there are gains from trade even for a country whose monopolistically competitive sector with heterogeneous firms is wiped out by the switch from autarky to trade. 
The analytical tractability of our model allows us to work out these effects in a very slim way and it also allows us to synthesize previous policy findings very compactly. The ease with which the model can be employed to address country asymmetries should make it an attractive tool to study the endogenous choice of policies and to address political economy applications in future work.

\section{References}

Baldwin, R., R. Forslid and P. Martin (2003), Economic Geography and Public Policy, Princeton University Press

Baldwin, R. (2005), Heterogeneous firms and trade: Testable and untestable properties of the Melitz model, NBER Working Paper 11471, Cambridge (Mass.)

Baldwin, R. and R. Forslid (2006), Trade liberalization with heterogeneous firms, NBER Working Paper 12192, Cambridge (Mass.)

Bernard, A., J. Eaton, B. Jensen and S. Kortum (2003), Plants and productivity in international trade, American Economic Review 93: 1268-1290

Chor, D. (2009), Subsidies for FDI: Implications from a model with heterogeneous firms, Journal of International Economics 78, 113-125

Cole, M. and R. Davies (2009), Optimal tariffs, tariff jumping, and heterogeneous firms, Working Paper, University College Dublin

Davis, D. R. and J. Harrigan (2008), Good Jobs, Bad Jobs, and Trade Liberalization, NBER Working Paper 13139, Cambridge (Mass.)

Davis, D. R. and D. Weinstein, (2001), An Account of Global Factor Trade, American Economic Review 91:5, 1423-1453

Demidova, S. (2008), Productivity improvements and falling trade costs: Boon or Bane. International Economic Review 49(4): 1437-1462

Demidova, S. and A. Rodríguez-Clare (2009), Trade policy under firm-level heterogeneity in a small economy, Journal of International Economics 78(1): 100-112.

Disney, R., J. Haskel and Y. Heden (2003), Restructuring and productivity growth in UK manufacturing. Economic Journal 113(489), 666-694

Dixit, A. and J. Stiglitz (1977), Monopolistic competition and optimum product diversity, American Economic Review 67: 297-308

Del Gatto, M., Mion, G., Ottaviano, G.I.P. (2006), Trade integration, firm selection and the costs of nonEurope. CEPR Discussion Paper 5730

Eckel, C. and H. Egger (2009), Wage bargaining and multinational firms, Journal of International Economics, Band 77, Nr. 2, 2009, S. $206-214$

Egger, H. and U. Kreickemeier (2009) .Firm Heterogeneity and the Labour Market Effects of Trade Liberalization,.International Economic Review, 50(1), 187-216

Falvey, R., D. Greenaway and Z. Yu (2005), Catching up or pulling away: Intra-industry trade, productivity gaps and heterogeneous firms, GEP Research paper 2005/18

Feenstra, R. and H. L. Kee (2008), Export variety and country productivity: Estimating the monopolistic competition model with endogenous productivity, Journal of International Economics, 74(2): $500-518$ 
Felbermayr, G., J. Prat and H.-J. Schmerer (2010) .Globalization and Labor Market Outcomes: Wage Bargaining, Search Frictions, and Firm Heterogeneity, Journal of Economic Theory, forthcoming

Flam, H. and E. Helpman (1987), Industrial policy under monopolistic competition, Journal of International Economics 22: 79-102

Helpman, E. and P. Krugman (1985), Market structure and foreign trade, Cambridge: MIT Press

Helpman, E. and P. Krugman (1989), Trade policy and market structure, Cambridge (Mass.): MIT Press

Helpman, E. (2006), Trade, FDI, and the Organization of Firms, Journal of Economic Literature 44 (3), 589-630

Helpman, E. and O. Itskhoki (2010), Labor Market Rigidities, Trade and Unemployment, Review of Economic Studies, 77 (3), 1100-1137

Helpman, E., O. Itskhoki and S. Redding (2010a), Inequality and Unemployment in a Global Economy, Econometrica, 78 (4), 1239-1283

Helpman, E., O. Itskhoki and S. Redding (2010b), Trade and Labor Market Outcomes, Frisch Lecture, Econometric Society World Congress, paper prepared for the conference monographs, forthcoming, 2011

Helpman, E., M. Melitz and Y. Rubinstein (2008), Estimating trade flows: Trading partners and trading volumes, Quarterly Journal of Economics 123: 441-487

Helpman, E., M. Melitz and S.R.Yeaple (2004), Export versus FDI with heterogeneous firms, American Economic Review 94(1): 300-316

Hopenhayn (1992), Entry, exit, and firm dynamics in long-run equilibrium, Econometrica 60: 1127-1150

Ikeda, Y. and W. Suoma (2009), International Comparison of Labor Productivity Distribution for Manufacturing and Non-Manufacturing Firms. Progress of Theoretical Physics Supplement No. $179,93-102$

Jorgensen, J. and P. Schröder (2008), Fixed export cost heterogeneity, trade and welfare, European Economic Review 52: 1256-1274

Martin, P. and C.A. Rogers (1995), Industrial Location and Public Infrastructure, Journal of International Economics 39: 335-351

Melitz (2003), The impact of trade on intra-industry reallocations and aggregate industry productivity. Econometrica 71(6), 1695-1725

Melitz, M. and G. Ottaviano (2008), Market size, trade, and productivity, Review of Economic Studies $75,295-316$

Pflüger, M. and J. Südekum (2009), Subsidizing Firm Entry in Open Economies, IZA Working Paper 4384

Redding, S. (2010), Theories of Heterogeneous Firms and Trade, CEP Discussion Paper 994

Schott, P. K. (2003), One Size Fits All? Heckscher-Ohlin-Specialization in Global Production, American Economic Review, 93:3, 686-708

Venables, A. (1987), Trade and trade policy with differentiated products: A Chamberlinian-Ricardian model, Economic Journal 97: 700-717 


\section{Appendices}

\section{Appendix A - Firm masses, the price level and indirect utility under autarky}

In equilibrium, the aggregate expenditure on manufacturing has to be equal to the aggregate revenue of manufacturing firms, $\beta L=\operatorname{Mr}(\tilde{\varphi})$. Using $r(\tilde{\varphi})=\left(\tilde{\varphi} / \varphi^{*}\right)^{\sigma-1} \sigma w f$, $\tilde{\varphi}=[k /(k-(\sigma-1))]^{1 /(\sigma-1)} \varphi^{*}$, and the equilibrium cutoff (5), the number of active firms can be derived, $M_{a u t}=\frac{\beta L[k-(\sigma-1)]}{\sigma k w f}$. The stationarity condition then implies the number of entrants, $M_{\text {aut }}^{E}=\frac{(\sigma-1) \beta L}{\sigma k w f_{e}}$. Using $M_{\text {aut }}$ and $\tilde{\varphi}=[k /(k-(\sigma-1))]^{1 /(\sigma-1)} \varphi^{*}$ in (4), yields the price level, $P_{\text {aut }}=(\beta L / \sigma f)^{1 /(1-\sigma)} w^{\sigma /(\sigma-1)}\left(1 / \rho \varphi_{\text {aut }}^{*}\right)$ and the indirect utility of a household is then as in eq. (6).

\section{Appendix B - The link between the productivity cutoffs in the open economy}

(i) From the ZCP conditions it follows that $r_{i}\left(\varphi_{i}^{*}\right)=\left(\rho \varphi_{i}^{*} P_{i}\right)^{\sigma-1} \beta L_{i}=\sigma w_{i} f_{i}$ and $r_{x i}\left(\varphi_{x i}^{*}\right)=\left(\tau_{i j} w_{i} / \rho \varphi_{x i}^{*}\right)^{1-\sigma} P_{j}^{\sigma-1} \beta L_{j}=\sigma w_{i} f_{x i}$. Consequently, we have

$$
\begin{gathered}
\frac{r_{H}\left(\varphi_{H}^{*}\right)}{r_{F}\left(\varphi_{F}^{*}\right)}=\frac{w_{H} f_{H}}{w_{F} f_{F}} \Rightarrow \frac{\varphi_{H}^{*}}{\varphi_{F}^{*}}=W^{-\sigma /(\sigma-1)} \frac{P_{F}}{P_{H}}\left(\frac{f_{H} L_{F}}{f_{F} L_{H}}\right)^{1 /(\sigma-1)} \\
\frac{r_{x H}\left(\varphi_{x H}^{*}\right)}{r_{x F}\left(\varphi_{x F}^{*}\right)}=\frac{w_{H} f_{x H}}{w_{F} f_{x F}} \Rightarrow \frac{\varphi_{x H}^{*}}{\varphi_{x F}^{*}}=W^{-\sigma /(\sigma-1)} \frac{\tau_{H F}}{\tau_{F H}} \frac{P_{H}}{P_{F}}\left(\frac{f_{x H} L_{H}}{f_{x F} L_{F}}\right)^{1 /(\sigma-1)} \\
\frac{r_{x i}\left(\varphi_{x i}^{*}\right)}{r_{i}\left(\varphi_{i}^{*}\right)}=\frac{f_{x i}}{f_{i}} \Rightarrow \frac{\varphi_{x i}^{*}}{\varphi_{i}^{*}}=\tau_{i j}\left(\frac{f_{x i}}{f_{i}}\right) \frac{P_{i}}{P_{j}}\left(\frac{L_{i}}{L_{j}}\right)^{1 /(\sigma-1)}
\end{gathered}
$$

Combining (B1) and (B3) leads to $\varphi_{x H}^{*}=W^{-\sigma /(\sigma-1)} t_{H} \varphi_{F}^{*}$ and $\varphi_{x F}^{*}=W^{\sigma /(\sigma-1)} t_{F} \varphi_{H}^{*}$ where $t_{i} \equiv \tau_{i j}\left(f_{x i} / f_{i}\right)^{1 /(\sigma-1)}$.

(ii) We assume that only firms that serve the domestic market can export, i.e. $\varphi_{x i}^{*}>\varphi_{i}^{*}$. From (B3) it follows that this holds true whenever $\tau_{i j}\left(f_{x i} / f_{i}\right)^{1 /(\sigma-1)}\left(P_{i} / P_{j}\right)\left(L_{i} / L_{j}\right)^{1 /(\sigma-1)}>1$. Substituting $P_{i}=\left(\beta L_{i} / \sigma f_{i}\right)^{1 /(1-\sigma)} w_{i}^{\sigma /(\sigma-1)}\left(\rho \varphi_{i}^{*}\right)^{-1}$ and rearranging yields $f_{x i} / f_{j}>\tau_{i j}^{1-\sigma}\left(w_{j} / w_{i}\right)^{\sigma}\left(\varphi_{i}^{*} / \varphi_{j}^{*}\right)^{\sigma-1}$.

Note that in Demidova (2008) the condition $\varphi_{x i}^{*}>\varphi_{i}^{*}$ implies $\varphi_{x i}^{*}>\varphi_{j}^{*}$ (i.e. that a domestic firm finds it easier to break even in its domestic market than a foreign exporter does) since her model 
assumes $W=1$. However, in the presence of a possibly large wage differential it is quite conceivable that an exporting firm might find it easier to break even than a local firm does. Hence, the implication will not carry over to our model, in general.

\section{Appendix C: Determination of equilibrium cutoffs in the open economy}

The free entry condition (FEC) for country $i$ is given by

$$
\left(1-G_{i}\left(\varphi_{i}^{*}\right)\right) \cdot E\left[\pi_{i}(\varphi) \mid \varphi>\varphi_{i}^{*}\right]+\left(1-G_{i}\left(\varphi_{x i}^{*}\right)\right) \cdot E\left[\pi_{x i}(\varphi) \varphi>\varphi_{x i}^{*}\right]=w_{i} \cdot f_{e i} \cdot \delta_{i}
$$

As $\pi_{i}(\varphi)=r_{i}(\varphi) / \sigma-w_{i} f_{i}$, we can write the expected domestic profits as

$$
E\left[\pi_{i}(\varphi) \mid \varphi>\varphi_{i}^{*}\right]=\frac{1}{\sigma} E\left[r_{i}(\varphi) \mid \varphi>\varphi_{i}^{*}\right]-w_{i} f_{i}
$$

Using $r_{i}(\varphi)=\left(\rho \varphi / w_{i}\right)^{\sigma-1} P_{i}^{\sigma-1} \beta L_{i}$ and the Pareto specification we get

$$
E\left[\pi_{i}(\varphi) \mid \varphi>\varphi_{i}^{*}\right]=\left(\frac{r_{i}\left(\varphi_{i}^{*}\right)}{\sigma} \frac{k}{k-\sigma+1}-w_{i} f_{i}\right)
$$

On substituting $r_{i}\left(\varphi_{i}^{*}\right)=\sigma w_{i} f_{i}$ which is implied by the domestic ZCPC $\pi_{i}\left(\varphi_{i}^{*}\right)=0$, we have:

$$
E\left[\pi_{i}(\varphi) \mid \varphi>\varphi_{i}^{*}\right]=\frac{\sigma-1}{k-\sigma+1} w_{i} f_{i}
$$

The expected export profits are determined in the same manner. Now we use export profits, export revenue, the previous parameterizations as well as the export ZCPC to obtain:

$$
E\left[\pi_{x i}(\varphi) \mid \varphi>\varphi_{x i}^{*}\right]=\frac{\sigma-1}{k-\sigma+1} w_{i} f_{x i}
$$

Substituting (C2) and (C3) into (C1) and using $G_{i}(\varphi)=1-\left(\varphi_{\min i} / \varphi_{i}\right)^{k} \quad$ yields $\frac{\sigma-1}{k-\sigma+1} \varphi_{\min i}^{k} f_{i}\left(\varphi_{i}^{*}\right)^{-k}+\frac{\sigma-1}{k-\sigma+1} \varphi_{\min i}^{k} f_{x i}\left(\varphi_{x i}^{*}\right)^{-k}=f_{e i} \cdot \delta_{i}$. Writing this equation out for $i=H, F$ and using the relationships between export cutoffs and domestic cutoffs, $\varphi_{x H}^{*}=W^{-\sigma /(\sigma-1)} t_{H} \varphi_{F}^{*}$ and $\varphi_{x F}^{*}=W^{\sigma /(\sigma-1)} t_{F} \varphi_{H}^{*}$ as derived in appendix B yields two equations which can be solved for the cutoffs $\varphi_{H}^{*}$ and $\varphi_{F}^{*}$ as stated in eq. (7).

\section{Appendix D: Firm masses, the price level and indirect utility under trade}

Start with the condition of balanced trade (eq. (8)) and substitute $M_{i}=\gamma_{i} L_{i} w_{i} / \bar{r}_{i}$ where $\bar{r}_{i} \equiv r_{i}\left(\tilde{\varphi}_{i}\right)+\operatorname{cprob}_{x i} r_{x i}\left(\tilde{\varphi}_{x i}\right), w_{H}=1 / a_{H}$ and $\beta\left(L_{H}+L_{F}\right)=\gamma_{H} L_{H} w_{H}+\gamma_{F} L_{F} w_{F}$. Solving for the $\gamma_{i}$ then gives: 


$$
\gamma_{H}=\frac{\beta}{w_{H}} \frac{\bar{r}_{H}}{r_{H}\left(\tilde{\varphi}_{H}\right)} \frac{1-\Phi_{F} / \Delta^{L, \varphi^{*}}}{1-\Phi_{H} \Phi_{F}} \quad \text { and } \quad \gamma_{F}=\frac{\beta}{w_{F}} \frac{\bar{r}_{F}}{r_{F}\left(\tilde{\varphi}_{F}\right)} \frac{1-\Phi_{H} \cdot \Delta^{L, \varphi^{*}}}{1-\Phi_{H} \Phi_{F}}
$$

where $\Delta^{L, \varphi^{*}} \equiv \frac{f_{F}}{f_{H}} \frac{L_{H}}{L_{F}} W^{\frac{k \sigma}{\sigma-1}}\left(\frac{\varphi_{F}^{*}}{\varphi_{H}^{*}}\right)^{k}=\frac{L_{H}}{L_{F}} \frac{\Delta^{\delta, f_{e}, \varphi \min , w}-\Phi_{F}}{1-\Delta^{\delta, f_{e}, \varphi \min , w} \Phi_{H}}$ is an increasing measure of relative conditions favoring business in $H$ (against $F$ ). Using $\gamma_{i}$, the masses of firms are immediately implied by $M_{i} \bar{r}_{i}=\gamma_{i} L_{i} w_{i}$ where $r_{i}\left(\tilde{\varphi}_{i}\right)$ follows from the domestic ZCPC and is given by $r_{i}\left(\tilde{\varphi}_{i}\right)=\sigma k f_{i} w_{i} /[k-(\sigma-1)]$. Hence, we have

$$
\begin{aligned}
& M_{H}=\frac{[k-(\sigma-1)] \beta L_{H}}{\sigma k f_{H} w_{H}} \cdot\left(\frac{1-\Phi_{F} / \Delta^{L, \varphi^{*}}}{1-\Phi_{H} \Phi_{F}}\right)=M_{H, \text { aut }} \cdot\left(\frac{1-\Phi_{F} / \Delta^{L, \varphi^{*}}}{1-\Phi_{H} \Phi_{F}}\right) \\
& M_{F}=\frac{[k-(\sigma-1)] \beta L_{F}}{\sigma k f_{F} w_{F}} \cdot\left(\frac{1-\Phi_{H} \Delta^{L, \varphi^{*}}}{1-\Phi_{H} \Phi_{F}}\right)=M_{F, \text { aut }} \cdot\left(\frac{1-\Phi_{H} \Delta^{L, \varphi^{*}}}{1-\Phi_{H} \Phi_{F}}\right)
\end{aligned}
$$

The number of exporting firms is implied by $M_{x i}=\operatorname{cprob}_{x i} M_{i}$ and the mass of entrants follows according to $M_{i}^{E}=\varphi_{\min i}^{-k} \varphi_{i}^{* k} \delta_{i} M_{i}$. The consumption variety available in country $i$ is $M_{t i}=M_{i}+M_{x j}$.

With the price setting rule defined by eq. (3), the price level can be rewritten as $P_{i}=M_{t i}{ }^{\frac{1}{1-\sigma}} \cdot p_{i}\left(\tilde{\varphi}_{t i}\right)$. The variable $\tilde{\varphi}_{t i}=\left\{\left(1 / M_{t i}\right)\left[M_{i} \tilde{\varphi}_{i}^{\sigma-1}+M_{x j}\left(w_{j} / w_{i}\right)^{1-\sigma} \tau_{j i}^{1-\sigma} \widetilde{\varphi}_{x j}{ }^{\sigma-1}\right]\right\}^{\frac{1}{\sigma-1}}$ can be interpreted as an average productivity of all firms (domestic and foreign) that serve consumers in country $i$. Consumers in country $i$ spend $M_{t i} r_{i}\left(\tilde{\varphi}_{t i}\right)=\beta L_{i}$ on manufacturing varieties and the average firm revenue is related to the revenue of the cutoff firm according to $r_{i}\left(\tilde{\varphi}_{t i}\right)=\left(\tilde{\varphi}_{t i} / \varphi_{i}^{*}\right)^{\sigma-1} r_{i}\left(\varphi_{i}^{*}\right)$. With $r_{i}\left(\varphi_{i}^{*}\right)=\sigma w_{i} f_{i}$ it follows that $M_{t i}=\beta L_{i}\left(\tilde{\varphi}_{t i} / \varphi_{i}^{*}\right)^{1-\sigma} / \sigma w_{i} f_{i}$. On substitution, this yields for the price level $P_{i}=\left(\beta L_{i} / \sigma f_{i}\right)^{1 /(1-\sigma)} w_{i}^{\sigma /(\sigma-1)}\left(\rho \varphi_{i}^{*}\right)^{-1}$. Notice that the derivation of the price level is independent from the derivation of the productivity thresholds and observe that it is completely general (it does not depend on the Pareto parameterization).

\section{Appendix E: The model with specialization on the traditional industry in $H$}

Consider that only $F$ has manufacturing firms, whereas country $H$ only produces the homogeneous good. The price indices are then given by $P_{s, F}=\left[\int_{z \in \Omega} p^{1-\sigma} M_{s, F} \mu_{F} d z\right]^{1 /(1-\sigma)}$ and 
$P_{s, H}=\left[\int_{z \in \Omega}\left(\tau_{F H} p_{F}\right)^{1-\sigma} M_{s, x F} \mu_{x F} d z\right]^{1 /(1-\sigma)}$ where $M_{s, F}$ and $M_{s, x F}$ is the number of domestic and exporting firms from $F$, respectively. Like under non-specialization, potential entrepreneurs in $F$ invest into the productivity lottery until the value of firm entry is driven to zero, so that the FEC is the same and is given by $\frac{\sigma-1}{k-\sigma+1} \varphi_{\min F}^{k} f_{F}\left(\varphi_{s, F}^{*}\right)^{-k}+\frac{\sigma-1}{k-\sigma+1} \varphi_{\min F}^{k} f_{x F}\left(\varphi_{s, x F}^{*}\right)^{-k}=f_{e F} \cdot \delta_{F}$. The trade balance condition from the perspective of $F$ is given by $M_{s, x F} r_{x F}\left(\tilde{\varphi}_{s, x F}\right)=L_{H} / a_{H}-\left(w_{H}-\beta\right) L_{H}$. The LHS gives the value of country $F$ 's manufacturing exports, whereas the LHS represents the difference between the value of domestic production and consumption of the homogeneous good. Using $1 / a_{H}=w_{H}$ and $r_{x F}\left(\tilde{\varphi}_{s, x F}\right)=\sigma k f_{x F} w_{F} /[k-(\sigma-1)]$ which follows from the export ZCPC $\pi_{F}\left(\varphi_{s, F}^{*}\right)=0$, the mass of exporting firms is given by $M_{s, x F}=[k-(\sigma-1)] \beta L_{H} / k \sigma w_{F} f_{x F}$. Furthermore, the total revenue of manufacturing firms must equal the sum of wages in that sector, i.e. $M_{s, F} \bar{r}_{F}=\gamma_{F} L_{F} w_{F}$ where $\bar{r}_{F} \equiv r_{F}\left(\widetilde{\varphi}_{s, F}\right)+\operatorname{cprob}_{x F} r_{x F}\left(\widetilde{\varphi}_{s, x F}\right)$ is the average revenue of a manufacturing firm in country $F$. Taking into account that worldwide expenditures on manufacturing goods must match the sum of wages earned in this sector, $\beta\left(L_{H}+L_{F}\right)=\gamma_{F} L_{F} w_{F}$, we derive the mass of domestic firms as $M_{s, F}=\frac{\beta\left(L_{H}+L_{F}\right)[k-(\sigma-1)]}{k \sigma w_{F}\left(f_{F}+\left(\varphi_{s, F}^{*} / \varphi_{s, x F}^{*}\right)^{k} f_{x F}\right)}$. Using $M_{x F}=\operatorname{cprob}_{x F} M_{F}$, where $\operatorname{cprob}_{x F}=\left(\varphi_{F}^{*} / \varphi_{x F}^{*}\right)^{k}$, shows that the domestic and the export cutoff are tied, $\varphi_{s, x F}^{*}=\left(\frac{L_{F}}{L_{H}} \frac{f_{x F}}{f_{F}}\right)^{1 / k} \varphi_{s, F}^{*}$. To ensure that only domestic firms can export, i.e. $\varphi_{s, x F}^{*}>\varphi_{s, F}^{*}$, we assume $\left(L_{F} / L_{H}\right)\left(f_{x F} / f_{F}\right)>1$. Using this link in the FEC yields the equilibrium cutoffs:

$$
\varphi_{s, F}^{*}=\varphi_{a u t, F}^{*} \cdot\left[1+L_{H} / L_{F}\right]^{1 / k} \text { and } \quad \varphi_{s, x F}^{*}=\varphi_{a u t, F}^{*} \cdot\left[f_{x F} / f_{F}\right]^{1 / k}\left[1+L_{F} / L_{H}\right]^{1 / k}
$$

The equilibrium masses of firms immediately follow by

$$
M_{s, F}=\frac{[k-(\sigma-1)] \beta L_{F}}{k \sigma w_{F} f_{F}} \quad \text { and } \quad M_{s, x F}=\frac{[k-(\sigma-1)] \beta L_{H}}{k \sigma w_{F} f_{x F}}
$$

To show that country $H$, which specializes in the homogeneous good, has gains from trade, we depart from the utility differential between the case with trade but no manufacturing firms in $H$ and autarky, $\Delta v \equiv v_{s, H}-v_{a u t, H}=\beta \ln \left(P_{a u t, H} / P_{s, H}\right)$. The utility differential is determined by the difference in price indices under autarky and specialization. Using 
$P_{s, H}=\left[\int_{z \in \Omega}\left(\tau_{F H} p_{F}\right)^{1-\sigma} M_{s, x F} \mu_{x F} d z\right]^{1 /(1-\sigma)}=\tau_{F H} M_{s, x F}^{1 /(1-\sigma)}\left(\rho \widetilde{\varphi}_{s, x F} / w_{F}\right)^{-1}$, the number of exporting firms from eq. (E2), $\widetilde{\varphi}=[k /(k-(\sigma-1))]^{1 /(\sigma-1)} \varphi^{*}$ and the equilibrium cutoffs as given by eq. (E1), the ratio of price indices is given by

$$
\left(\frac{P_{a u t, H}}{P_{s, H}}\right)^{k}=\Phi_{F} \Delta_{\delta, f_{e}, \varphi \min , w}^{1}\left[1+\frac{L_{F}}{L_{H}}\right]
$$

From eq. (D1) we know that there are no manufacturing firms in $H$ whenever $\Delta^{L, \varphi^{*}} \leq \Phi_{F}$, or $\Phi_{F} \Delta_{L, \varphi^{*}}^{1} \geq 1$, respectively. Hence, it immediately follows from (E3) that there are gains from trade even if trade opening forces country $H$ into full specialization on the traditional good. 